\title{
Bitcoin Piyasasında Balonlar: Genelleştirilmiş Eküs ADF Testi*
}

\section{Bubbles in Bitcoin Markets: Generalized Sup ADF Test}

\author{
Mehmet Songur a,** \\ ${ }^{a}$ Dr. Öğr. Üyesi, Dicle Üniversitesi, İktisadi ve İdari Bilimler Fakültesi, İktisat Bölümü, 21280, Diyarbakır/Türkiye. \\ ORCID: 0000-0003-4763-9314
}

MAKALE BİLGİSİ
Makale Geçmişi:
Başvuru tarihi:
Düzeltme tarihi:
Kabul tarihi:

Anahtar Kelimeler:

Bitcoin

Spekülatif Balonlar

GSADF Testi

\section{ARTICLE INFO}

\section{Article history:}

Received

Received in revised form

Accepted

\section{Keywords:}

Bitcoin

Speculative Bubbles GSADF Test

\begin{abstract}
ÖZ
İnternet kullanımındaki hızlı gelişmeler ile birlikte, insan hayatına fiziksel olarak dahil olan para da dijitalleşmeye başlamıştır. Bu tür dijitalleşmiş para birimlerine genel olarak kripto para denilmektedir. Hali hazırda, Bitcoin, kripto para birimleri arasında en yüksek işlem hacmine sahiptir. İlk Bitcoin 2009 yılında piyasaya sürüldü. Fakat son birkaç yılda ciddi derecede ilgi çekmeye başladı. Bu ilginin temel nedenlerinden birisi, Bitcoin'in değerinde önemli artışların olmasıdır. Söz konusu değer artışları bağlamında, Bitcoin piyasasında spekülatif balonların varlığının araştırılması önem arzetmektedir. Bu bağlamda, çalışmanın amacı 2015-2018 dönemi boyunca Bitcoin piyasasında spekülatif balonların varlığını araştırmaktır. Amaç doğrultusunda, spekülatif balonların tespiti için Phillips vd. (2015) tarafından geliştirilen Genelleştirilmiş Eküs ADF testi kullanılmıştır. Elde edilen bulgular,Bitcoin piyasasında çok sayıda baloncuk olduğunu göstermektedir.
\end{abstract}

\begin{abstract}
A B S T R AC T
Along with the rapid developments in the use of internet, the money that is physically involved in human life has also started to be digitalized. Such digitizedcurrencies are generally called crypto currencies. Currently, Bitcoin has the highest transaction volume among the crypto currencies. The first bitcoin was released in 2009. However, in the last few years it has started to attract considerable attention. One of the main reasons for this interest is the significant increase in the value of Bitcoin. In the context of these increases, it is important to investigate the existence of speculative bubbles in the Bitcoin market. In this context, the aim of this study is to investigate the presence of speculative bubbles in the Bitcoin market during the period 2015-2018. In line with the purpose, Generalized Sup ADF test developed by Phillips et al. (2015) is used to detect speculative bubbles. The results show that there are many bubbles in the bitcoin market.
\end{abstract}

\section{Giriş}

Günümüzden yaklaşık iki veya üç yüzyıl önce yaşamış olsaydınız, büyük ihtimalle paranızın küçük bir kısmı kâğıt paralardan, büyük bir kısmı ise değerli madenlerden (altın ve gümüş gibi) yapılmış -genel adı ile- sikkelerden oluşacaktı. Yaklaşık 10 yıl öncesine kadar ise insanların paraları, merkezi para otoriteleritarafından basılmış madeni ve kağıt paralardan, bankaların merkez bankalarının kontrolü altında ellerinde tuttukları mevduat hesaplarından veya resmi paranın elektronik karşılığı olan e-paralardan oluşmakta idi. Bugün ise artık bu para türlerine ek olarak yeni bir para çeşidi olan kripto paralardan söz ediyoruz.

Kripto para (cryptocurrency), kripto (crypto) ve para birimi anlamina gelen (currency) kelimelerin birleşiminden oluşmaktadır. $\mathrm{Bu}$ kavramı anlayabilmek için kriptoloji kavramını açmakta fayda vardır. Kriptoloji, bir şifre bilimi olup, bir bilginin istenmeyen taraflarca ele geçirilmesini önlemek amacı ile gerçekleştirilen tekniklerin tamamı olarak ifade edilebilir. Kripto para ise, kriptoloji ile güvenliği sağlanan, herhangi bir aracı kuruluşa bağlı olmayan dijital ve sanal ortamlarda kullanilabilen sanal

\footnotetext{
*Bu çalışma, 14-17 Kasım 2018 tarihlerinde Diyarbakır'da düzenlenen International Social Sciences and Education Conference (ISSEC 2018)'de sunulan "Bitcoin Piyasasında Çoklu Balonlar: Genelleştirilmiş EküsADF Testi” başlıklı bildirinin gözden geçirilmiş ve genişletilmiş halidir.

**Sorumlu yazar/Corresponding author

e-posta: mmtsngr@gmail.com
} 
para birimleri şeklinde tanımlanabilir. Kripto paraların en önemli özelliği herhangi bir merkezinin ya da herhangi bir otoritenin altında olmamasıdır. İlk çıkan ve küresel nitelikte olan kripto paralar bu özelliğe uymaktadır. Bununla birlikte son birkaç yıldır ülkeler ulusal kripto paralarını -örneğin Venezuela Petro'su gibi- çıkarmakta ya da çıkarmayı planlamaktadırlar. Ülkelerin çıkardıkları bu kripto paralar ise,ilk çıkan kripto paraların merkezi otorite baskısı altında olmama özelliğinden ayrıșmaktadır.

Günümüzde 2000'in üzerinde kripto para vardır. Bugün itibari ile bu kripto paralardan ilki ve en iyi bilineni Bitcoin'dir. Bitcoin, Satoshi Nakamoto tarafindan 2008 yılında yayımlanan bir makale ile duyurulmuş ve sistemin nasıl işlediği bu makalede anlatılmıştır. Nakamoto çalışmasında önerdikleri para sistemini tamamen eşten eşe çalışan, herhangi bir aracı finansal kuruluş içermeyen, çevrimiçi ödeme gönderilmesini mümkün kılan ve bunu gerçekleştirebilmek için de dijital imzaları sistemin bir parçası olarak kabul eden bir sistem olarak tanımlamıştır. Mükerrer harcamaları önlemek için finansal aracıların kullanılması durumunda sistemin tüm özelliklerini yitireceğini belirterek, bu sorunun önüne geçmek için de eşler arası ağ kullanılmasını önermiş̧lerdir. Söz konusu ağ, işlemleri sürekli uzayan özet fonksiyonu tabanlı bir iş kanıtı zincirine eklemekte ve zaman damgasıyla işaretlemektedir. $\mathrm{Bu}$ çerçevede iş kanıtını tekrar üretmeden değiştirilemez bir kayıt oluşturmaktadır (Nakamoto, 2008).

Çalışmanın amacı, 1 Ocak 2015-4 Ekim 2018 dönemi boyunca Bitcoin piyasasında spekülatif balonların varlığını araştırmaktır. Başlangıç tarihinin 1 Ocak 2015 olarak alınmasının temel nedeni, Bitcoin'e ilişkin fiyatlamaların söz konusu dönem sonrasında daha fazla dalgalanmasına neden olmasıdır. Ayrıca Bitcoin ile ilgili bahsi geçen yıldan itibaren küresel çapta artan oranda medya ilgisi, bilgi ve duyumların yayılması söz konusudur. Amaç doğrultusunda, spekülatif balonların tespiti için Phillips vd. (2015) tarafından geliştirilen Genelleştirilmiş Eküs ADF testi kullanılmıştır. $\mathrm{Bu}$ testin en önemli özelliği, dinamik bir yapıya sahip olması nedeni ile spekülatif balonların ele alınan dönem boyunca kaç defa ortaya çıktığının ve ne kadar süre ile devam ettiğinin tahmin edilebilmesine olanak sağlamasıdır. Çalışmanın ikinci bölümündeBitcoin ve spekülatif balonlar irdelenecektir. Üçüncü bölümde Bitcoin'e ait ampirik literatür üzerinde durulacaktır. Dördüncü bölümde ele alınan yöntem sunulacaktır. Beşinci bölümde, çalışmada kullanılan veri seti hakkında bilgi verildikten sonra analizden elde edilen bulgular paylaşılacaktır. Altıncı bölümde ise, çalışmadan elde edilen bulgulara ilişkin sonuçlar irdelenecektir.

\section{Bitcoin ve Spekülatif Balonlar}

İlk Bitcoin transferi 3 Ocak 2009 tarihinde yapılmıştır. Zamanla Bitcoin birçok alışveriş işlemi içerisinde kullanılarak reel ekonomiye bir şekildedahil edilmiştir.
Bununla birlikte Bitcoin birçok yasadıșı iș için (silah veya uyuşturucu alımı ya da kara para aklama gibi) kullanılmaya da başlanmıştır. Günümüzde de bu tarz kullanımlar devam etmektedir. $\mathrm{Bu}$ durum Bitcoin'in imajına oldukça zarar vermekte ve birçok ülke Bitcoin kullanımını bu durumları da dikkate alarak yasaklamaktadır.

Bitcoin ile gerçekleştirilen tüm işlemler ağ içerisinde kronolojik sıra ile kaydedilmektedir. Bu, kişilere ait sanal cüzdanlar aracılığı ile yapılmakta ve bir blok zinciri (blockchain) oluşturulmaktadır. Blok zinciri, bir merkeze bağlı olmadan ve aracı kuruluşlar olmaksızın alıcı ile satıcı arasında güvenli bir alışveriş gerçekleştirilmesine olanak sağlamaktadır. Merkezi otoritenin ve aracı kuruluşların olmaması mevcut sistemin temellerine yapılmış bir saldırı olarak nitelendirilebilir. Bununla birlikte, mevcut sistem içerisinde yer alan merkezi otoriteler ve aracı kuruluşlar bu teknolojiyi kendi sistemlerine entegre etmiş ya da bu yönde çalışmalarına başlamışlardır. Bu durum kripto para teknolojisinin önemini ortaya koymaktadır.

Kripto paraların en önemli özelliklerinden bir tanesi, para arzının sınırlı olmasıdır. Örneğin şu anda kullanımda olan ya da henüz kullanıma alınmamış toplam Bitcoin miktarı 21 milyondur. Günümüzde kullanılan kâğıt ya da madeni paralar bir merkezden piyasaya arz edilmektedir. Fakat Bitcoin gibi kripto paralar bir merkezden arz edilmemektedir. $\mathrm{Bu}$ paralar tüm kullanıcıların geçekleştirebilecekleri, bilgisayarlar aracılığı ile çeşitli matematiksel problemleri çözen bir yazılım aracılığ 1 ile elektronik ortamda basılmaktadır. Bu işleme kripto para madenciliği (mining) adı verilmektedir.

2009 yllında ilk kez piyasaya sürülmesine rağmen Bitcoin gibi kripto para sistemleri henüz oldukça yeni sistemlerdir. $\mathrm{Bu}$ nedenle fiyatlamaları çok yüksek oynaklıklara sahiptir. $\mathrm{Bu}$ paralara yönelik olumlu (satış esnasında Bitcoin kabul eden firma sayısının artması, medya ya da internet ilgisi gibi) ya da olumsuz (çeşitli hükümetlerin Bitcoin'e ilişkin yasakları gibi) haberler fiyat oluşumlarında yüksek oynaklıklara yol açmaktadır. Buna ek olarak birçok insan tarafından Bitcoin gibi kripto paraların güvenilirliği hala ciddi sorgulamalara tabi tutulmaktadır. Dolayısı ile oynaklığın yüksek olması yatırımcılar açısından önemli derecede fiyat riskine neden olmaktadır. $\mathrm{Bu}$ nedenle kısa süre içerisinde büyük kazançlar sağlayabildiği gibi ani kayıpların ortaya çıkmasına da neden olmaktadır. Şekil 1'de Bitcoin'in ilk piyasaya sürüldüğü tarihten günümüze kadar olan süreçte ABD Doları cinsinden piyasa fiyatı grafiği verilmiştir. Grafikten de anlaşılacağı üzere Bitcoin fiyatlamaları özellikle 2016 sonrasında ciddi fiyat dalgalanmalarına, diğer bir ifade ile oynaklıklara sahiptir. $\mathrm{Bu}$ oynaklıklara ek olarak Bitcoin gibi kripto paraların denetimden uzak olması, merkezinin ve aracı kuruluşların olmaması gibi nedenler göz önüne alındığında fiyatlamalar sırasında spekülatif balonların ortaya çıkması muhtemeldir. 


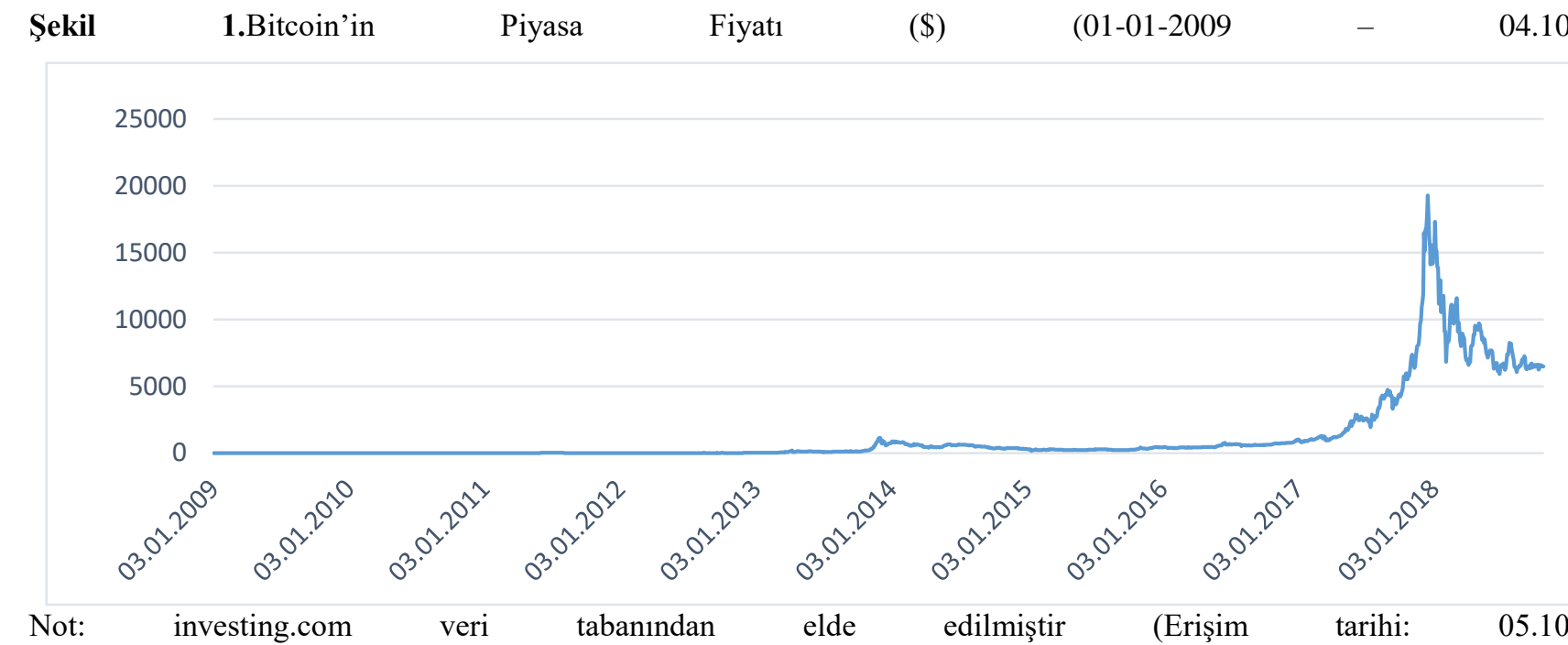

04.10.2018)

$.10 .2018)$

Ekonomik balon olarak da adlandırılan spekülatif balonlar, bir malın gerçek değerinin üzerinde fiyat oluşumları ile ticaretinin yapılması olarak ifade edilebilir. Santoni (1987) finansal piyasalarda balonu, bir varlığın sürekli olarak gerçek değerinden daha yüksek değerler alması olduğunu belirtmiştir. Blanchard ve Watson (1982) ise, yatırımcıların bir finansal varlığ beklentisi ile gerçek değerinin üzerinde bir değerden satın aldığında stokastik bir balon oluşacağını ifade etmişlerdir. Kindleberger (2000) bir finansal varlığın fiyatının hızlı bir şekilde artmasını baloncuklar olarak tanımlarken, Schiller (2005) bu baloncukların ortaya çıkmasını sağlayan ilk artışın, yeni alıcıları genellikle irrasyonel bir coşkunluk olarak adlandırılan bir süreç sonunda fazla artış beklentisi yaratması olarak ifade etmiştir. Balonların varlığ 1 söz konusu varlığa ait piyasanın etkin olmadığını ve bu piyasalarda rasyonel kararlar alınmadığını göstermektedir. Rasyonel beklentiler hipotezine göre, bir finansal varlık sadece piyasa temellerine göre fiyatlanmalıdır. Ancak finansal varlıklar, piyasanın keyfi ve kendi kendine gerçekleştirilen beklentilerle fiyatlanan bir fiyat kabarcığ yaratabilmesi olasıdır. Söz konusu bu kabarcıklar devam ederse, "irrasyonel kabarcıklar" ortaya çıkacaktır.

\section{Literatür}

Bitcoin 2009 yılında piyasaya sürüldükten sonra zaman ilerledikçe çeşitli kullanım alanları bulmuş ve yatırımcıların artan ilgisi ile karşılaşmıştır. Bu durum Bitcoin'in bilimsel bir temelde incelenmesini de beraberinde getirmiş olup, Bitcoin ve kripto paralara yönelik akademik çalışmaların sayısı hızlı bir şekilde artmıştır. İlgili literatüre bakıldığında ekonomik çalışmaların bir kısmı Bitcoin'i teorik olarak incelerken, bir kısmı ampirik olarak incelemiştir. Bu çalışmada, literatürde yer alan ampirik çalışmalardan farklı bir amaç taşımamaktadır. Dolayısıyla Bitcoin'in ampirik olarak analiz edilmesi bağlamında literatüre katkı sağlama motivasyonundan hareket etmektedir.

İlgili literatüre baktığımızda Briere vd. (2013) Bitcoin'in yüksek getiri sağlamasına karşın yüksek oynaklığa sahip olması nedeni ile uzun vadede risklerin ortaya çıkabileceğini belirtmişlerdir. Bununla birlikte, geleneksel yatırım araçları ile korelasyonunun düşük olması nedeniyle, portföy çeşitlendirmesinde önemli yararlar sağlayabileceğini ifade etmişlerdir. Fink ve Johann (2014) göre ise, Bitcoin fiyatlamalarında meydana gelen yüksek oynaklık yüksek getiri sağlamaktadır. Gün (2014) ise, işlem maliyetlerinin az olması, uluslararası işlem görmesi gibi faydaları olmasına rağmen Bitcoin'inspekülatif balonlar oluşturabileceğini belirtmiş ve bunun nedeni olarak gözetimden uzak olmasını göstermiştir.

Vockathaler (2015), GARCH modeli ile Bitcoin'in günlük fiyatlarındaki oynaklığı araştırdığı çalışmasında, Bitcoin fiyatlamalarıda meydana gelen dalgalanmaların içsel bir süreç tarafından modellendiğini ve bu dalgalanmalara bilinmeyen şokların neden olduğunu tespit etmiştir. Kristoufek (2015) ise, literatürde yer alan çalışmaların aksine Bitcoin'in spekülatif olmadığı sonucuna ulaşmıştır. Ancak Bitcoin fiyatlamalarında meydana gelen aşırı dalgalanmalar göz önüne alındığında Bitcoin'in güvenilir bir yatırım aracı olmadığını da vurgulamıştır.

Bitcoin piyasasında yukarıda yer verdiğimiz çalışmalardan farklı olarak bir de spekülatif balonların varlığını araştıran çalışmalar da mevcuttur. İlk olarak Grinberg (2011) çalışmasında, Bitcoin'in arz ve talebine göre irrasyonel kabarcıklara duyarlı olduğunu ifade etmiştir. Ancak bu iddiasını ampirik olarak kanıtlamamıştır. Dowd (2014) Bitcoin fiyatlarının spekülatif kabarcıklar içerdiğini ampirik olarak ifade etmiştir. Benzer şekilde MacDonell (2014) Bitcoin fiyatlarındaki eğilimi analiz etmiş ve 2013 sonlarında baloncuklar olduğunu doğrulamıştır. Hatta bu spekülatif balonların Bitcoin'in değerinin belirlenmesinde motive eden birincil güç olduğunu iddia etmiştir. Cheah ve Fry (2015), Bitcoin fiyatlamalarında kabarcıklar olduğunu belirtmişlerdir. Ancak Baloncukların sayısını ve hangi tarihlerde gerçekleştiğini belirtmemişlerdir. Daha sonra Fry ve Cheah (2016) çalışmalarında, Bitcoin piyasasının önemli spekülatif bileşen içerdiğini ve aşırı derecede balon olduğunu ifade etmişlerdir. Ceylan vd. (2018), çalışmalarında Bitcoin için 01.01.2015-31.03.2018 dönemine ait verilerle GSADF birim kök testini kullanarak spekülatif balonların varlığını araştırmıştır. Bulgular ele alınan dönemde birçok balon olduğunu göstermektedir. Delikanlı ve Vogiazas (2018) çalışmalarında SADF ve GSADF birim kök testleri ile Bitcoin piyasasında 
spekülatifbalonların varlığını araştırmışlar ve elde ettikleri bulgulara göre Bitcoin fiyatında çok sayıda balon olduğunu belirtmişlerdir.

\section{Yöntem}

Spekülatif balonların varlığını ve ne zaman gerçekleştiklerini tahmin etmek için Phillips vd. (2011) Dickey ve Fuller (1979) tarafından geliştirilen ADF birim kök testini geliştirerek eküs (sup) ADF birim kök testini sunmuşlardır. Ancak SADF birim kök testi literatürde, ele alınan dönemde birden fazla balon söz konusu olduğunda istatistiksel olarak testin gücü azalması nedeniyle önemli eleştirilere tabi tutulmuştur. Bu nedenle, Phillips vd. (2015) SADF birim kök testinin genelleştirilmiş versiyonu olan GSADF testini sunmuşlardır. GSADF testinde ADF birim kök testinde yer alan regresyon denklemi, tekrarlanan (recursive) esnek tahmin pencereleri kullanılarak koşturulmaktadır. Bu bağlamda GSADF testi uzun zaman serilerinde karşılaşılan yapısal kırılmaları ve doğrusal olmayan yapıları dikkate almaktadır. Böylelikle, çok sayıda balonun olduğu durumda SADF testine göre daha tutarl bulgular elde edilebilmektedir.

Phillips vd. (2015)'de yer alan metodoloji izlendiğinde, GSADF testinde, yokluk hipotezi herhangi bir $y_{t}$ serisinin, asimtotik olarak ihmal edilebilir bir kayma ile (1) numaralı denklemde yer alan rassal yürüyüş sürecini takip ettiği varsayılır:

$y_{t}=d T^{-\eta}+\theta y_{t-1}+\varepsilon_{t}, \varepsilon_{t} \sim i i d\left(0, \sigma^{2}\right), \theta=1$

Bu denklemde $d$ sabiti, $T, \eta>1 / 2$ iken gözlem sayısını ve $\varepsilon_{t}$ ise sifir ortalama ve sabit varyanslı (i.i.d.) hata terimini ifade etmektedir. Alternatif hipotez ise, $\theta>1$ iken $y_{t}$ serisinde oluşan balonların varlığını göstermektedir.

GSADF testinde, test istatistiğini hesaplamak için, yinelemeli esnek tahmin pencereleri kullanılarak (2) numaralı regresyon denklemi tahmin edilir:

$$
\Delta y_{t}=\hat{\alpha}_{r_{1}, r_{2}}+\hat{\beta}_{r_{1}, r_{2}} y_{t-1}+\sum_{i=1}^{k} \hat{\psi}_{r_{1}, r_{2}}^{i} \Delta y_{t-i}+\hat{\varepsilon}_{t}
$$

$\mathrm{Bu}$ denklemde $\mathrm{k}$ gecikme uzunluğunu, $r_{1}$ ve $r_{2}$ sirası ile yinelemeli regresyon tahminlerine ait alt örneklemlerin başlangıç ve bitiş noktalarını vermektedir. ADF test istatistiği her bir alt örneklem için (3) numaralı eşitlikteki gibi elde edilir:

$$
A D F_{r_{1}, r_{2}}=\beta_{r_{1}, r_{2}} / \operatorname{se}\left(\beta_{r_{1}, r_{2}}\right)
$$

$\mathrm{Bu}$ eşitlikte se standart hataları ifade etmektedir. GSADF test istatistiğinin elde edilebilmesi için, (2) numaralı eşitlikteki regresyon denklemi birden çok alt örneklem için ileri tarihli olacak şekilde tahmin edilir. Her bir tahminden yinelenen să̆ kuyruklu ADF testleri elde edilir. Tüm örneklemin 0 ile 1 arasında olduğu varsayılırsa [0,1], alt örneklemlerin başlangıç noktası $\left[0, r_{2}-r_{0}\right]$ aralığında, bitiş noktası ise $\left[r_{0}, 1\right]$ aralığında değişen değerler alır. Burada yer alan $r_{0}$ minimum tahmin penceresi uzunluğudur. $\mathrm{Bu}$ çerçevede GSADF test istatistiği (4) numaralı eşitlikteki gibi elde edilebilir:

$$
\operatorname{GSADF}\left(r_{0}\right)=\sup _{r_{2} \in\left[r_{0}, 1\right], r_{1} \in\left[0, r_{2}-r_{0}\right]}\left\{A D F_{r_{1}}^{r_{2}}\right\}
$$

Ele alınan zaman serisindeki balonların tespit edilebilmesi için örneklem son gözlemden ilk gözlemlere doğru geriye dönük (backwards) dizisi oluşturulur. BSADF dizisi, geriye doğru genişleyen örneklemler üzerine uygulanan sağ kuyruklu ADF testleriyle edile edilir. Bitiş noktası $\left(r_{2}\right)$ sabit olmak koşulu ile başlangıç noktaları 0 noktasından $r_{2}-$ $r_{0}$ 'a kadar değişen alt örneklemler için tahmin edilen ve (5) numaralı eşitlikte yer alan ADF dizisi bağlamında, BSADF istatistiği (6) numaralı eşitlikteki gibi ifade edilebilir:

$$
\begin{gathered}
\left\{A D F_{r_{1}}^{r_{2}}\right\}_{r_{1} \in\left[0, r_{2}-r_{0}\right]} \\
B S A D F_{r_{2}}\left(r_{0}\right)=\sup _{r_{1} \in\left[0, r_{2}-r_{0}\right]}\left\{A D F_{r_{1}}^{r_{2}}\right\}
\end{gathered}
$$

Elde edilen BSADF dizisi Monte Carlo simülasyonu ile elde edilen her bir istatistiğe ait sağ kuyruk dağılımlı kritik değerler dizisi ile karşılaştırılır. Spekülatif balonların başlama ve bitiş tarihlerine ilişkin tahminler aşağıda yer alan kriterler çerçevesinde yapılır:

$$
\begin{aligned}
& \hat{r}_{e}=\inf _{r_{2} \in\left[r_{0}, 1\right]}\left\{r_{2}: B S A D F_{r_{2}}\left(r_{0}\right)>s c v_{r_{2}}^{\beta_{T}}\right\} \\
& \hat{r}_{f}=\inf _{r_{2} \in\left[\hat{r}_{e}+\delta \log (T) / T, 1\right]}\left\{r_{2}: B S A D F_{r_{2}}\left(r_{0}\right)>s c v_{r_{2}}^{\beta_{T}}\right\}
\end{aligned}
$$

Eşitliklerde yer alan $s c v_{r_{2}}^{\beta_{T}}, r_{2}$ gözlem sayısı için BSADF istatistiğinin $\% 100\left(1-\beta_{T}\right)$ kritik değerini göstermektedir. T örneklem büyüklüğünü ifade etmektedir. Balonun başlangıç tarihi $T \hat{r}_{e}$, BSADF istatistiğinin kritik değeri aştığ 1 ilk gözlem, balonun bitiş tarihi $T \hat{r}_{e}$ ise, en az $\left[T \hat{r}_{e}\right]+\delta \log (T)$ gözlem sonra BSADF dizisi ilk kez kritik değerin altına düştüğü gözlem tarihidir.

\section{Bulgular}

Çalışmada Bitcoin piyasasında balonların varlığını araştırmak için dolar cinsinden Bitcoin fiyatları kullanılmıştır. Analizde 1 Ocak 2015 ile 4 Ekim 2018 dönemlerine ait günlük Bitcoin fiyatları veri setimizi oluşturmaktadır. Veri seti investing veri (investing.com) tabanından elde edilmiştir. Başlangıç yılı olarak 1 Ocak 2015 alınmasının temel nedeni, söz konusu dönemden itibaren Bitcoin fiyatlarında önemli hareketlerin görülmesidir. Bu durum Şekil 1'de de görülebilir. Tablo 1'de ilgili veri setine ait bazı betimsel istatistikler sunulmuştur.

Tablo 1.Betimsel İstatistikler

\begin{tabular}{ll}
\hline GözlemSayısı & 1373 \\
Ortalama & 2952.71 \\
Enyüksek & 19187 \\
Endüşük & 183 \\
Çarpıklık & 1.552 \\
Basıklık & 4.869 \\
JarqueBera & 750.96 \\
\hline
\end{tabular}

Çalışmada 1373 gözlemlik bir zaman serisi ele alınmıştır. Bitcoin'in ortalama değeri 2952.71 iken en yüksek değer 
19187'dir. Bu durum Bitcoin'in fiyat seviyelerinde önemli sapmaların olduğunu göstermektedir. Ayrıca Bitcoin serisi sağa çarpık ve basık bir özellik sergilemektedir. Jarque Bera tet istatistiği ise Bitcoin serisinin normal dağılmadığını göstermektedir. Bu istatistikler ele alınan dönemde Bitcoin serisinde balonlar olabileceği yönünde bir ön bilgi sunmaktadır.

Tablo 2.GSADF Test Sonuçları

\begin{tabular}{ll}
\hline Test İstatistiği & $12.682^{*}$ \\
\%95 KritikDeğer & 2.409 \\
PencereUzunluğu & 80 \\
Gecikme & 0 \\
\hline
\end{tabular}

Not: * notasyonu $\% 5$ düzeyinde istatistiksel olarak anlamlılı̆̆ 1 ifade etmektedir. Kritik değerler 2000 tekrarlı Monte Carlo simülasyonundan elde edilmiştir.

Tablo 2'de GSADF birim kök testi sonuçları sunulmuştur. Elde edilen bulgulara göre test istatistiği kritik değerden büyüktür. $\mathrm{Bu}$ bağlamda yokluk hipotezi reddedilerek, balonların varlığını ileri süren alternatif hipotez kabul edilmiştir. Dolayısı ile hangi tarihlerde spekülatif balon olduğunun tespit edilmesi gerekmektedir.
Şekil 2'de elde edilen BSADF dizileri, Monte Carlo simülasyonundan \%95 güven aralığında elde edilen kritik değer dizisi ile karşılaştırılmıştır. BSADF dizisinin kritik değer dizisinden büyük olduğu her tarih (gri sütunlar) spekülatif balonu göstermektedir.

Söz konusu balon tarihlerinin daha detaylı sunumu Tablo 3'de sunulmuştur. Buna göre ele alınan dönemde toplam 9 adet spekülatif balon söz konusudur. En uzun süreli balon 20 Nisan 2017 ile 15 Ocak 2018 tarihleri arasında 271 gün süre ile gerçekleşmiştir.

Tablo 3.1 Ocak 2015 - 4 Ekim 2018 Tarihleri Arasında Bitcoin Balon Tarihleri

\begin{tabular}{ccc}
\hline BalonSayıs & Balon Tarihleri & Süre \\
$\mathbf{1}$ & $10.07 .2015-12.07 .2015$ & 3 gün \\
$\mathbf{2}$ & $02.11 .2015-09.11 .2015$ & 8 gün \\
$\mathbf{3}$ & $11.12 .2015-19.12 .2015$ & 9 gün \\
$\mathbf{4}$ & $28.05 .2016-21.06 .2016$ & 25 gün \\
$\mathbf{5}$ & 02.07 .2016 & 1 gün \\
$\mathbf{6}$ & $27.10 .2016-02.11 .2016$ & 7 gün \\
$\mathbf{7}$ & $22.12 .2016-05.01 .2017$ & 15 gün \\
$\mathbf{8}$ & $17.02 .2017-15.03 .2017$ & 27 gün \\
$\mathbf{9}$ & $20.04 .2017-15.01 .2018$ & 271 gün \\
\hline
\end{tabular}

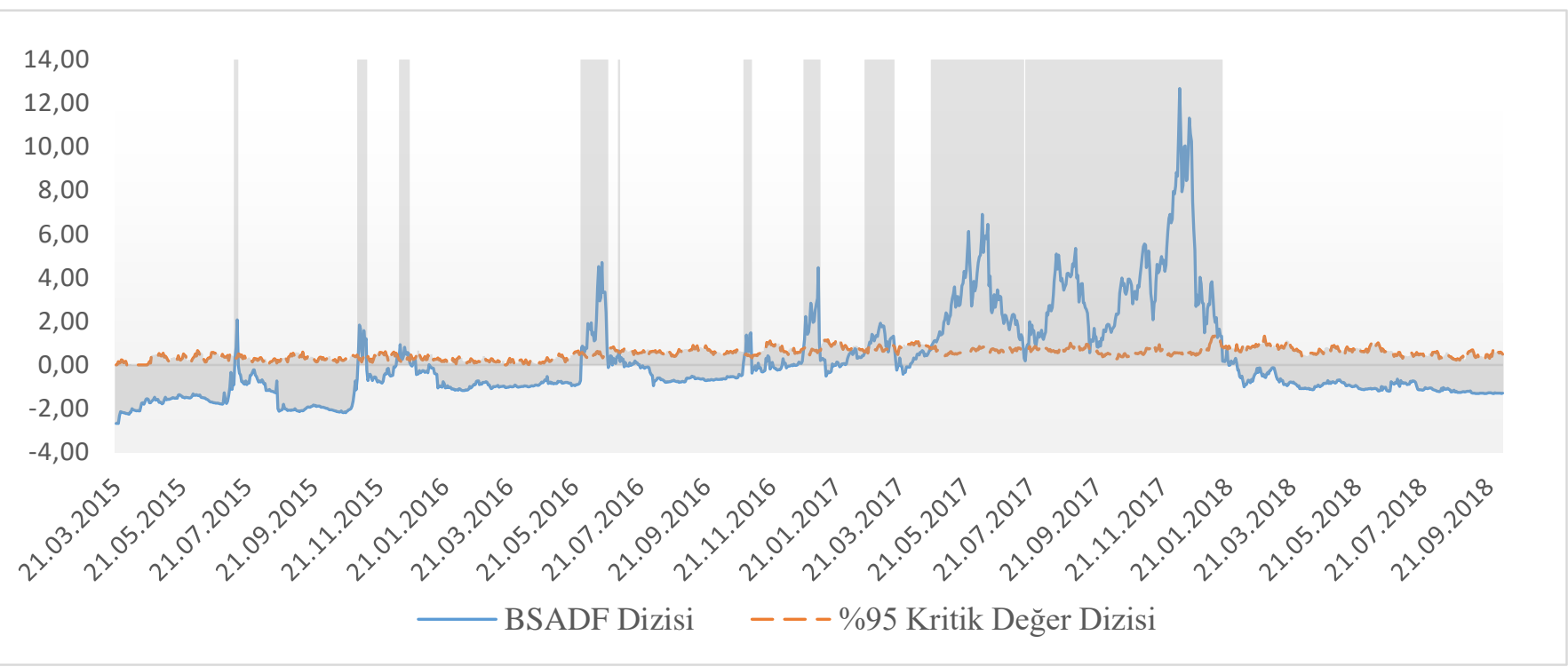

Şekil 2. BSADF Dizileri

\section{Sonuç ve Değerlendirme}

Bu çalışmada en yüksek işlem hacmine sahip ve en değerli kripto para birimi olan Bitcoin'in 1 Ocak 2015 ile 4 Ekim 2018 tarihleri arasındaki fiyatlamalarında spekülatif balonların varlığı araştırılmıştır. Bu amaçla GSADF birim kök testi çalışmada kullanılmıştır. Bulgular,Bitcoin'de ele alınan dönemde 9 adet spekülatif balonun olduğunu göstermektedir. Bu balonlar içerisinde en uzun süreli balon, 20 Nisan 2017 ile 15 Ocak 2018 tarihleri arasında 271 gün süre ile gerçekleşmiştir. Bu durumun birçok nedeni vardır. Bunlardan birincisi ve en önemlisi 2017 yılı itibari ile Bitcoin dünya çapında birçok ünlü uzman tarafindan tartışılmaya başlanmıştır. Bu durum Bitcoin'in bilinirliğini arttırmış ve ciddi bir farkındalığa yol açmıştır. İkincisi bu dönemde Bitcoin dünya çapında birçok firma tarafından ticari işlemlerde kabul edilmeye başlanmıștır. Dahası bazı ülkeler -örneğin Japonya- çeşitli yasal düzenlemeler ile
Bitcoin'i yasallaştırmaya başlamıştır. Bu iki durum fiyat artışlarına neden olmuştur. Fiyat artışları ile beraber Bitcoin'e yönelik yatırımcı ilgisinde meydana gelen artışlar da Bitcoin'de meydana gelen fiyat artışlarını desteklemiştir. Bunlara ek olarak dünyanın önde gelen vadeli işlem borsaları (Chicago Board Options Exchange ve Chicago Mercantile Exchange gibi) Bitcoin'de vadeli işlemleri başlatmışlardır. Bu durumun Bitcoin'e bir meşruiyet kazandırdığı söylenebilir.

Diğer taraftan, her ne kadar ele alınan dönemin sonunda spekülatif balonların azalış eğiliminde olduğu gözlemlense de, Bitcoin piyasasının ilerleyen dönemde süpekülatif balonlar yaratmaya meyilli olduğu ifade edilebilir. Bu balonların varlığı ve ilerleyen dönemde devam etme potansiyeli olduğu dikkate alındığında,Bitcoin yatırımcılarının söz konusu durumu dikkate alarak yatırımlarını gerçekleştirmeleri nispeten daha doğru olacaktır. Ayrıca Bitcoin'in en önemli özelliği bir değişim 
aracı olmasıdır. Bitcoin'in tanınırlığı ve değişim aracı olma özelliği önplana çıktıkça fiyatlamalarında daha az spekülatif balon olabileceği ifade edilebilir.

Tüm bunlara ek olarak, çalışmadan elde ettiğimiz bulgular literatürde yer alan çalışmalarla (Dowd, 2014; MacDonell, 2014; Cheah ve Fry, 2015; Fry ve Cheah, 2016; Delikanlı ve Vogiazas, 2018) tutarlılık sergilemektedir. Ayrıca Ceylan vd. (2018)'nin çalışması da ele alınan dönem ve Bitcoin'in balon içermesi bağlamında çalışmamızla tutarlılık sergilediği ifade edilebilir. Bununla birlikte söz konusu çalışmada elde edilen balon tarihlerinin çalışmamızdan elde edilen tarihlerle birebir tutarlılık sergilemediği gözlemlenmektedir. $\mathrm{Bu}$ durumun temel nedeni, yaklaşık 200 gözlem çalışmamızda daha fazla gözlem olması ve söz konusu tahminlerin simülasyon tahminlerindeki farklılaşmalardan kaynaklandığı ifade edilebilir.

\section{Kaynakça}

Blanchard, O. J., \& Watson, M. W. (1982). Bubbles, Rational Expectations and Financial Markets. NBER working paper, No. 945. (Erişim Tarihi: 09/12/2018), https://www.nber.org/papers/w0945

Briere, M., Oosterlinck, K., \& Szafarz, A. (2013). Virtual currency, tangible return: Portfolio diversification with Bitcoins. Journal of International Financial Markets, Institutions and Money, 16(6), 365-373.

Ceylan, F., Tüzün, O., Ekinci, R., \& Kahyaoğlu, H. (2018). Kripto Para Piyasalarında Finansal Balonlar (Bubbles): Bitcoin ve Etherium. İçinde: Bayar, Y. (Ed.), 4th SCF International Conference on Economic and Social Impacts of Globalization and Future of Turkey-EU Relations Proceedings Book, Uşak.

Cheah, E. T., \& Fry, J. (2015). Speculative bubbles in Bitcoin markets? An empirical investigation into the fundamental value of Bitcoin. Economics Letters, 130, 32-36.

Delikanlı, İ. U., \& Vogiazas, S. (2018). Testing for the presence of speculative price bubbles in Bitcoin. Istanbul Ticaret Üniversitesi Sosyal Bilimler Dergisi, 17(33), 511-523.

Dickey, D. A., \& Fuller, W. A. (1979). Distribution of the estimators for autoregressive time series with a unit root. Journal of the American Statistical Association, 74(366a), 427-431.

Dowd, K. (2014). New Private Monies: A Bit-Part player? London: Institute of Economic Affairs.
Fink, C., \& Johann, T. (2014). Bitcoin Markets. (Erișim Tarihi: 09/12/2018). https://papers.ssrn.com/sol3/papers.cfm?abstract_id=24 08396

Fry, J., \& Cheah, E. T. (2016). Negative bubbles and shocks in cryptocurrency markets. International Review of Financial Analysis, 47, 343-352.

Grinberg, R. (2011) Bitcoin: An innovative alternative digital currency. Hastings Science \& Technology Law Journal, 4(1), 160-206.

Gün, L. (2014). A new form of currency: Description and economic principle. Journal of Scientific Research and Reports, 3(13), 81-93.

Kindleberger, C. P. (2000). Manias, panics, and crashes: a history of financial crises. The Scriblerian and the KitCats, 32(2), 379.

Kristoufek, L. (2015). What are the main drivers of the Bitcoin price? Evidence from wavelet coherence analysis. PLoS ONE, 10(4): e0123923.

MacDonell, A. (2014). Popping the Bitcoin Bubble: An Application of Log-Periodic Power Law Modeling to Digital Currency. University of Notre Dame working paper, (Erișim: 09/12/2018). https://economics.nd.edu/assets/134206/mac_donell_po pping_the_biticoin_bubble_an_application_of_log_peri odic_power_law_modeling_to_digital_currency.pdf

Nakamoto, S. (2008). A peer-to-peer electronic cash system. (Erişim: 28/10/2018), https://bitcoin.org/bitcoin.pdf

Phillips, P. C. B., Shi, S., \& Yu, J. (2015). Testing for multible bubbles: Historical episodes of exuberance and collapse in the S\&P 500. International Econmic Review, 56(4), 1043-1078.

Phillips, P. C. B., Wu, Y., \& Yu, J. (2011). Explosive behavior in the 1990s Nasdaq: When did exuberance escalate asset values. International Econmic Review, 52(1), 201-226.

Santoni, G. J. (1987). The great bull markets 1924-29 and 1982-87: Speculative bubbles or economic fundamentals?. Federal Reserve Bank of St. Louis Review, 69(9), 16-30.

Shiller, R. J. (2005). Irrational exuberance. Princeton: Princeton University Press.

Vockathaler, B. (2015). The Bitcoin Boom: An In Depth Analysis of The Price Of Bitcoins. (Erişim Tarihi: 09/12/2018), https://ruor.uottawa.ca/bitstream/10393/32888/1/Vockat haler_Brian_2015_researchpaper.pdf 